\title{
ON THE SYNONYMY OF ORUSSUS SAYII WESTWOOD ${ }^{1}$
}

\author{
By HaRry D. PratT
}

Specimens of the genus Orussus Latr. are comparatively rare in most insect collections. Therefore it was with some surprise that the author discovered on June 25, 1935, near his summer home in Jacksonville, Vermont, a dead sugar maple (Acer saccharum) with at least twenty specimens of Orussus on it. Orussus has the habit of jumping, almost like a Haltica, before flying and then returns often almost to exactly the same spot from which it flew. Collection is most easily made by covering them with a wide-mouth cyanide jar, since they frequently fly out under the side of a net if it is snapped against the side of the tree. Subsequent collecting in 1936 and 1937 has shown that $O$. sayii Westwood emerges as early as May 31 in 1936, while O. terminalis Newman persists at least until mid-July.

If Mr. H. E. Burke's article (Proc. Ent. Soc. Wash., 1917, vol. 19: pages 87-88) is correct, and "Oryssus is Parasitic" on Buprestidae, then the host is likely to be a species of Dicerca, probably divaricata Say, since what appears to be this species occurs commonly in the same tree.

Careful examination and dissection of $O$. sayii showed that this species occurred only in the male sex, while O. terminalis occurred only in the female. This fact in itself would make one suspicious as to the synonymy of the two, and becomes all the more interesting from a biological viewpoint, since it is a well-known fact that in parasitic Hymenoptera the males usually emerge before the females, the reason apparently being that they can mate with the larger females as the latter emerge, while they are still somewhat teneral and unable to resist the advances of the male. As mentioned earlier, $O$. sayii emerges before $O$. terminalis, usually a week

${ }^{1}$ Contribution from the Entomological Laboratory of Massachusetts State College, Amherst, Mass. 
earlier. This fact should be significant in declaring the two synonymous.

S. A. Rohwer (Proc. Ent. Soc. Wash., 1917, vol. 19: p. 95) wrote, "We have not yet been able to locate a male to go with this female (O. terminalis), and it is possible that the male of the species will have the abdomen entirely black and that it is at present confused under the name sayii."

In view of Mr. Rohwer's statement, and judging from some hundred and more specimens collected from a single tree over a period of three years, it seems quite probable that $O$. sayii and $O$. terminalis are the sexes of the same species, which, according to priority, should be called Orussus sayii Westwood, since it was described in 1835, while Newman's species was not described until 1838.

It may be of interest here to note that the figure of Orussus terminalis in H. H. Ross' "Generic Classification of the Nearctic Sawflies" on plate IX, fig. 169 belongs to sayii. According to a letter from Dr. Ross, the specimen does have the abdomen black and would key out to sayii.

The synonymy of the species then is as follows:

Oryssus sayii Westwood, Zool. Journ., 1835, vol. 5: p. 440.

Oryssus terminalis Newman, Ent. Mag., 1838, vol. 5: p. 486 (New Synonymy).

Oryssus haemorrhoidalis Harris, Rept. Ins. Mass., 1841: p. 394 (Synonymy by Rohwer, Proc. Ent. Soc. Wash., 1917, vol. 19: p. 95). 

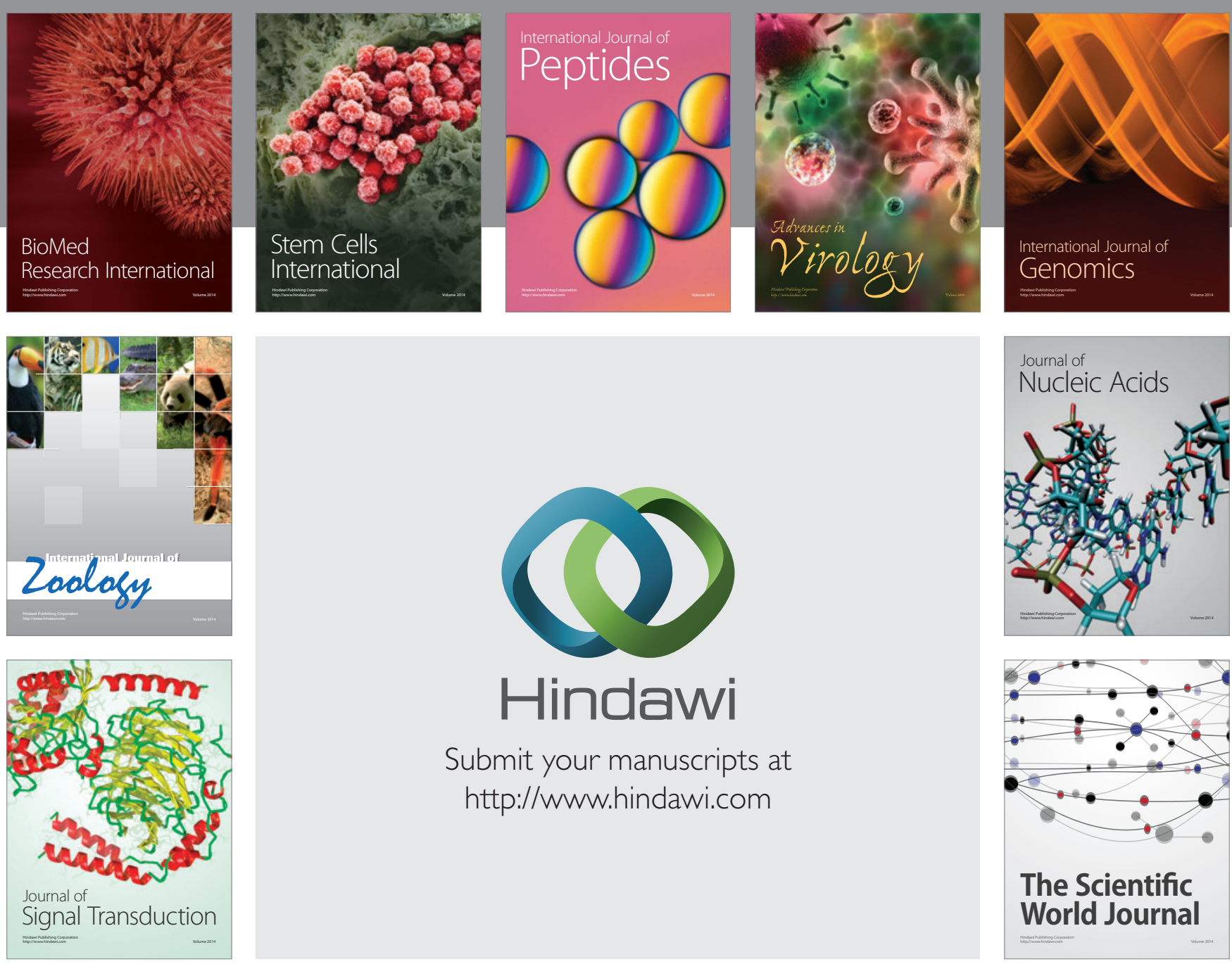

Submit your manuscripts at

http://www.hindawi.com
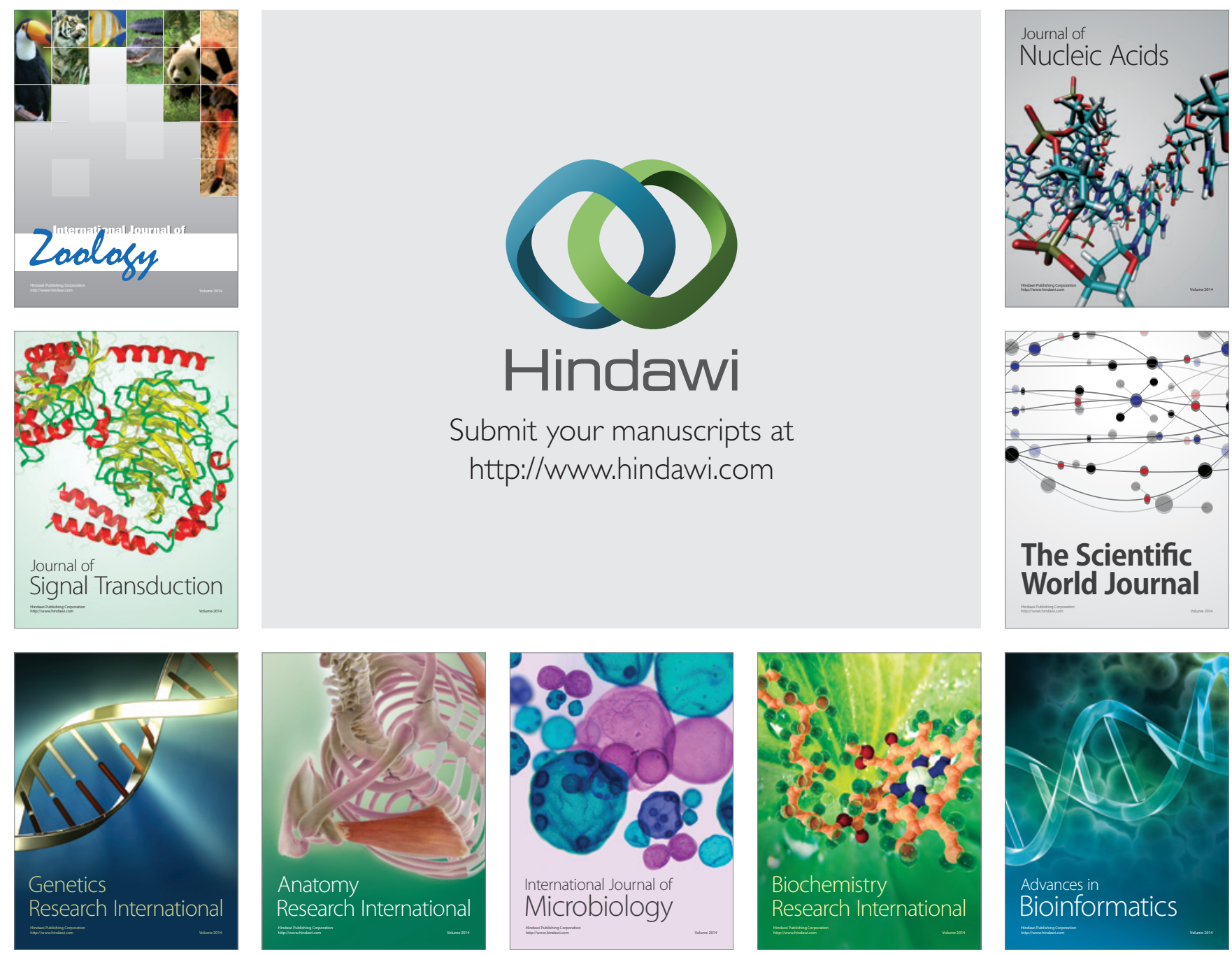

The Scientific World Journal
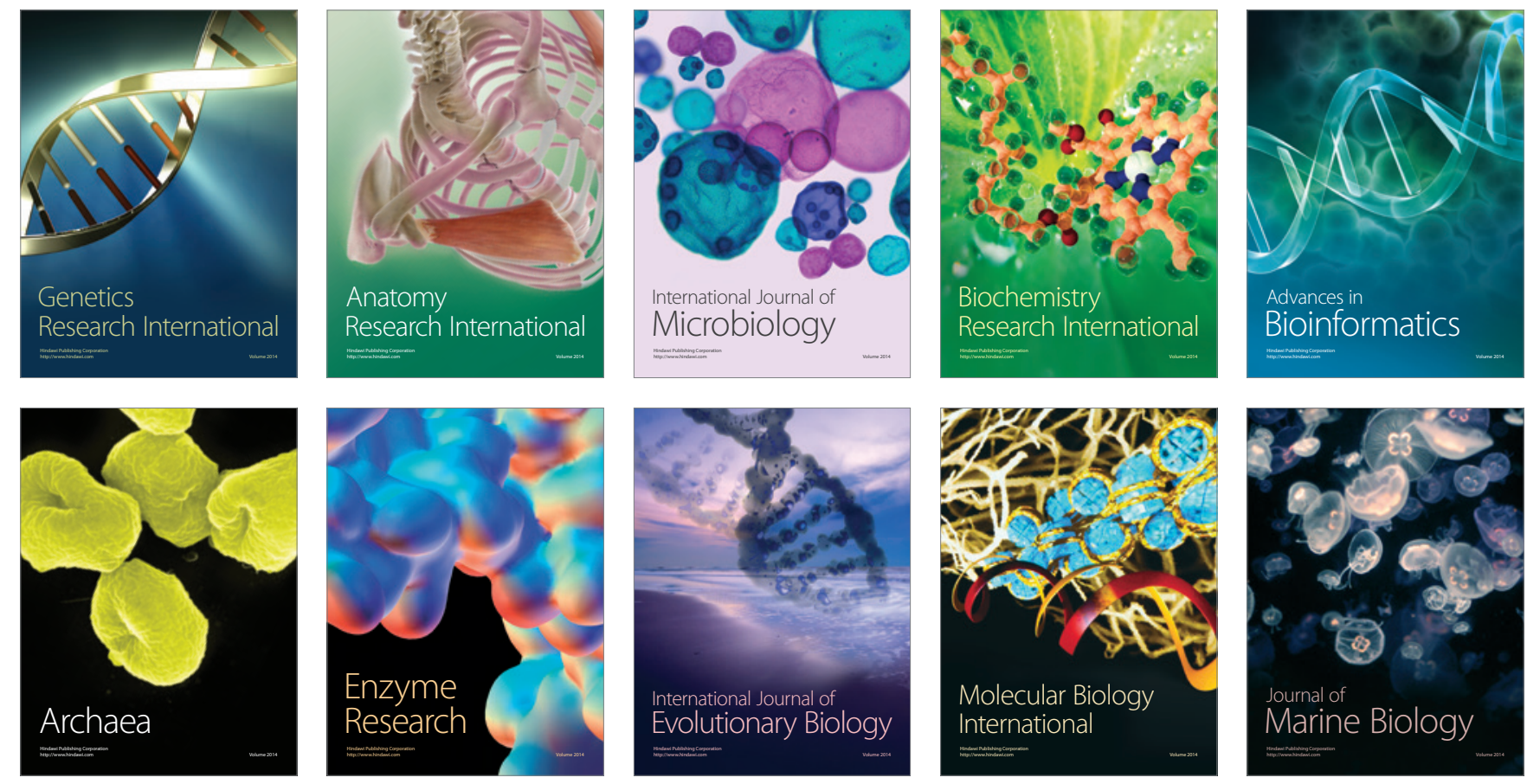